\title{
Application of the S7-200PLC and KINGVIEW6.53to the constant pressure water supply system with variable frequency
}

\author{
Bai Yan ${ }^{1, a}$,Sun Bei ${ }^{2, b}$ Zhang Zhiyi ${ }^{3, c}$ \\ ${ }^{1}$ BeiHua University Engineering Training Center \\ ${ }^{2}$ Beihua University Mechanical Engineering College \\ ${ }^{3}$ Beihua University Mechanical Engineering College \\ abyw1689@sohu.com, b745575912@qq.com
}

Keywords:variable frequency and speed regulation.water supply of constant pressure.PID control system.PLC

\begin{abstract}
With the rapid development social economy, on one hand, people's request to enhance the quality of water supply and the water supply system reliability is increased continuously.The design of the system is the VF water supply systems that controlled by PLC of Siemens S7-200 series and Kingview software.and have developed good operation management interface using Supervision Control and Data Acquisition.The operation results show that this system have constant water pressure,simple structure and high reliability.
\end{abstract}

\section{Introduction}

With the rapid development social economy,people on water quality and water supply to demand for improved system reliability; coupled with the current energy shortage, low-carbon living into a lifestyle, the use of advanced automation technology,control technology and communication technology ${ }^{[1]}$,making the different areas of constant pressure water supply system to achieve high performance, high-energy into technology trends.

According to the requirement of water supply in the oil company, a set of automatic system of constant pressure water supply by using variable frequency and remote monitoring and controlling, which is composed of PLC, transducer ${ }^{[2]}$,pressure sensor, pumps and electro-motors, computer and device of communication is designed to that end. This set of system has the functions like automatic constant pressure operation by using variable frequency, automatic work frequency operation, and the function of long-range control by hand and the on-the-spot control by hand etc. The system has solved efficiently the problem existing in the traditional way of water supply, which has various supplementary functions to strengthen the reliability .The system has an organic combination with computer and promotes the systematic overall performance,and have developed good operation management interface using Supervision Control and Data Acquisition ${ }^{[3]}$.

\section{Composition of constant pressure water supply system}

The water supply system of frequency control of constant voltage changes by PLC, frequency converter, unit, electrical cupboard and pressure to send ware and word control machine etc. composition. This system is formed by 4pump generators,3mainpump generators form the circulating run mode of frequency conversion.With general frequency converter realize of three-phase pump generator soft stat with frequency control, operation switch adopts the principle of "start first stop first"[4]. Another little pump generator adopts the run mode of constant speed, make system in water consumption low very much, can stop all main pumps, mend water with little pump, reduce little systematic power consumption and noise. The detection signal of pressure sensor of hydraulic pressure, via PLC with set value by carry out PID comparison operation, so, control frequency and the export voltage of frequency converter, and then the rotational speed that changes pump generator come to change water supply quantity ,eventually, it is nearby to maintain pipe net pressure to stabilize when set value. Through work control machine the connection with PLC, with KINGVIEW group form software consummately systematic monitoring, have realized operation state development to show and data, report to the police inquiry[5]. 


\section{.Variable frequency constant pressure water supply system}

Variable frequency constant pressure water supply system diagram as shown in Fig 1.

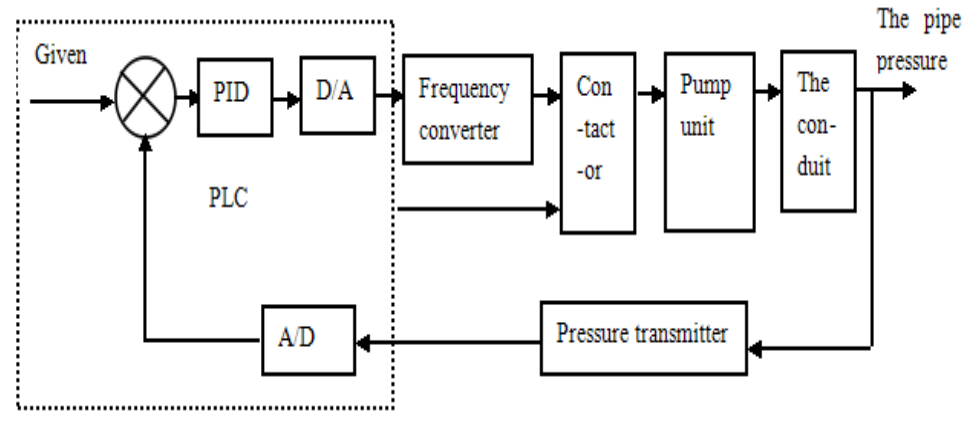

Figure 1.

\section{Electrical control requirements}

When the initial state, $1 \#$ pump variable frequency starting, speed from the beginning of 0 with the frequency increasing, If the variable frequency reaches $50 \mathrm{~Hz}$ and hydraulic pressure is still lower value, after a period of time delay (to avoid the interference caused by malfunction), The 1\# pump is switched to power frequency operation, At the same time, the frequency of the inverter is reduced from $50 \mathrm{~Hz}$ to $0 \mathrm{~Hz}$, 2\# pump frequency conversion start, If the water pressure is still not satisfied, then start 3\#, 4\# pump, The switching process of pump; If the start of 1\# pump standby, directly start 2\# variable frequency, from the beginning of 0 with the frequency increasing speed,if the inverter frequency reaches $50 \mathrm{~Hz}$ while who is still lower limit, delay time, pump switch to $2 \#$ frequency operation,If the $1 \#$ pump, $2 \#$ pump standby, directly start the $3 \#$ pump frequency, if the water pressure is still not satisfied, then a startup 4\# pump, 5\# pump, 6\# pump, the switching process.

\section{The design of PLC program}

In plant life water as an example system of constant pressure water supply system program, PLC input/output allocation table as shown in Table1.PLC control procedures such as shown in Table2.

Tablel PLC input / output allocation

\begin{tabular}{|c|c|c|c|c|c|}
\hline \multicolumn{6}{|c|}{ PLC input and output distribution table } \\
\hline $\mathrm{N}_{0 .}$ & Address & function & No. & Address & function \\
\hline 1 & $\mathrm{I} 0.0$ & l\# pump frequency start / stop & 8 & $\mathrm{I} 0.7$ & $2 \#$ pump frequency operation \\
\hline 2 & $\overline{I 0.1}$ & l\# pump frequency conversion start / stop & 9 & Il.0 & 2\# pump frequency conversion operation \\
\hline 3 & I0.2 & l\# pump frequency operation & 10 & Il.1 & 2\# Pump motor thermal protection \\
\hline 4 & $\mathrm{I} 0.3$ & l\# pump frequency conversion operation & 11 & Il.2 & Inverter fault \\
\hline 5 & $\mathrm{I} 0.4$ & l\# pump motor thermal protection & 12 & Il.5 & Function \\
\hline 6 & $\mathrm{I} 0.5$ & 2\# pump frequency start / stop & 13 & Il.6 & Zer0 \\
\hline 7 & $\mathrm{I} 0.6$ & l\# pump frequency conversion start / stop & 4 & Q0.3 & The inverter contactor \\
\hline $\bar{l}$ & Q0.0 & l\# pump frequency operation & 5 & Q0.5 & Fault display \\
\hline 2 & Q0.1 & The inverter contactor & 6 & Q0.6 & The operation of the transducer \\
\hline 3 & Q0.2 & 2\# pump frequency operation & & & \\
\hline
\end{tabular}


Table2 PLC control procedures

\begin{tabular}{|c|c|c|c|c|c|}
\hline \multicolumn{6}{|c|}{ the control program } \\
\hline Network & 1 & $=$ & M0.2 & $\ldots$ & \\
\hline LD & $\mathrm{I} 0.0$ & Network & 5 & Network & 14 \\
\hline $\mathrm{A}$ & Il.5 & LD & $\mathrm{M} 0.2$ & LD & I0.6 \\
\hline AN & M0.6 & AN & M0.3 & AN & M0.3 \\
\hline EU & & LD & M0.2 & AN & M0.6 \\
\hline$=$ & M0.0 & $\mathrm{A}$ & $\mathrm{M} 0.3$ & AN & $\mathrm{I} 0.7$ \\
\hline Network & 2 & LD & T38 & $\mathrm{A}$ & Il.5 \\
\hline LD & M0.0 & AN & I0.7 & EU & \\
\hline AN & M0.1 & OLD & & $=$ & M0.7 \\
\hline LD & M0.0 & 0 & Ml.1 & Network & 15 \\
\hline 0 & $\mathrm{I} 0.4$ & NOT & & LD & M0.7 \\
\hline A & M0.1 & $\mathrm{A}$ & M0.3 & $\mathrm{A}$ & Ml.0 \\
\hline LD & T37 & OLD & & 0 & Ml.1 \\
\hline AN & $\mathrm{I} 0.2$ & $=$ & $\mathrm{M} 0.3$ & LDN & Ml.0 \\
\hline 0 & Ml.1 & Network & 6 & CTD & $\mathrm{C} 2,1$ \\
\hline OLD & & LD & M0.3 & Network & 22 \\
\hline$=$ & M0.1 & NOT & & LD & M0.6 \\
\hline Network & 3 & Network & 7 & 0 & Ml.0 \\
\hline LD & M0.1 & LD & Il.5 & $=$ & Q0.4 \\
\hline TON & $\mathrm{T} 37,+10$ & $\mathrm{~A}$ & Il0.1 & Network & 23 \\
\hline Network & 4 & 0 & T39 & LD & M0.6 \\
\hline LD & Il.5 & AN & M0.1 & $=$ & Q0.1 \\
\hline 0 & Il.6 & $\mathrm{AN}$ & Ml.0 & Network & 25 \\
\hline $\mathrm{A}$ & $\mathrm{I} 0.5$ & AN & I0.2 & LD & Il.5 \\
\hline AN & Ml.0 & EU & & 0 & Il.6 \\
\hline $\mathbf{E U}$ & & $=$ & M0.4 & $=$ & Ml.1 \\
\hline
\end{tabular}

\section{PID control and its control algorithm AND Configuration interface design}

$$
\begin{aligned}
& y(t)=K_{p}\left[e(t)+\frac{1}{T_{i}} \int e(t) d t+T_{d} \frac{d e(t)}{d t}\right] \\
& G(s)=\frac{U(s)}{E(s)}=K_{P}\left(1+\frac{1}{T_{i} s}+T_{d} s\right)
\end{aligned}
$$

The system can be approximated as a first order inertial link with pure lag[6], the process of transfer function: $W_{O}(s)=\frac{2}{300 s+1} e^{-300 s}$ The inverter can be approximated as a proportion of links, $W_{V}(s)=50$.The feedback loop transfer function: ${ }^{\prime}(s)=0.03$ Because the system has the self regulating ability,The PI controller transfer function:

$$
W_{C}(s)=\frac{1}{3}\left(1+\frac{1}{240 s}\right)=\frac{240 s+1}{720 s}
$$

Using MATLAB simulation software, programming is as follows:

$\mathrm{s} 1=\mathrm{tf}(2,[300,1]) ; \mathrm{s} 2=\mathrm{tf}([240,1],[720,0]) ; \mathrm{sk}=\mathrm{s} 1 * \mathrm{~s} 2 * 50 ; \mathrm{s}=$ feedback(sk,0.03);step(s);

Simulation waveforms obtained after operation is shown in Fig 2.configuration interface design is shown in Fig 3. 


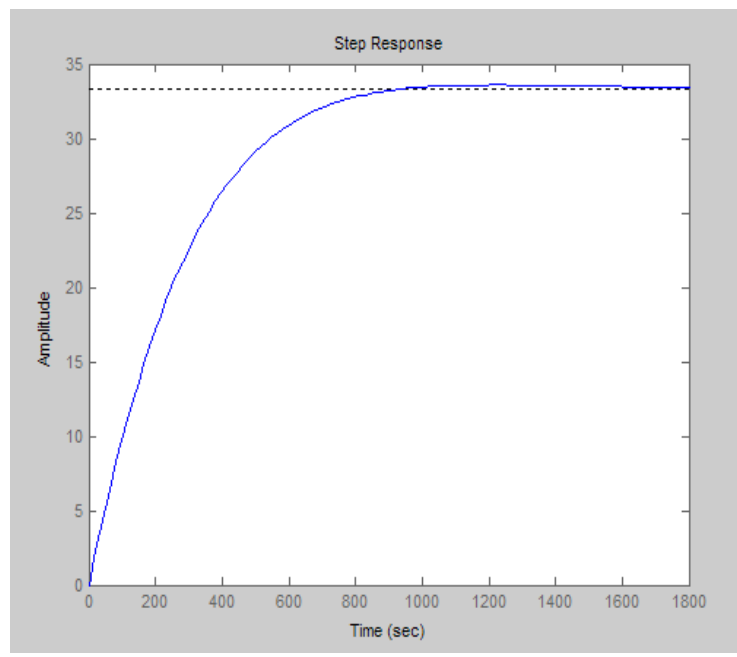

Figure2.

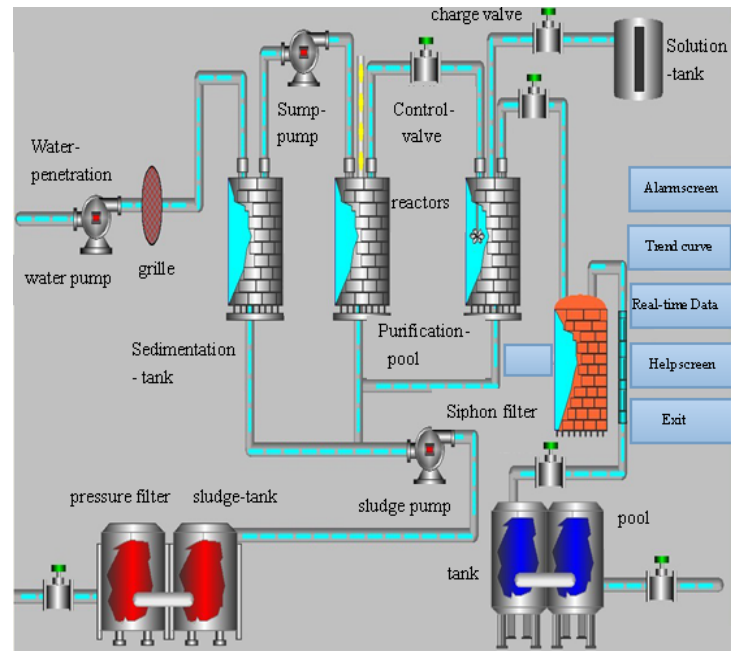

Figure3.

\section{Conclusion}

The system has solved efficiently the problem existing in the traditional way of water supply,which has various supplementary functions to strengthen the reliability .The system has an organic combination with computer and promotes the systematic overall performance,and have developed good operation management interface using Supervision Control and Data Acquisition.The whole scheme is safe and reliable, economical and practical, convenient operation.

\section{References}

[1].Lindberg C F,Carlsson B.Nonlinear and set-point control of thedissolved oxygen concentration in an activated sludge process. Water Science and Technology . 1996

[2].GALLUZZO M,DUCATO R,BARTOLOZZI V,PICCIOTTO A.Expert control of DO in the aero-bi reactor of an activated sludge process. Computers\&Chemical Engineering . 2001

[3].M Batty.The AJAX project:New theory, and new software for space syntax[J].SPACE SYNTAX 5TX INTERNATIONAL SYMPOSIUM 2005,VOL 1,PROCEEDINGS.2005,(12/1):10 11

[4].Chen J C,Chang N B.Assessing wastewater reclamation potential by neural network model. Engineering Applications of Artificial Intelligence . 2003

[5].Du Y G,Tyagi R D,Bhamidimarri R.Use of fuzzy neural-net model for rule generation of activated sludge process. Process Biochemistry . 1999 